\title{
Neglect of other health services during the corona crisis
}

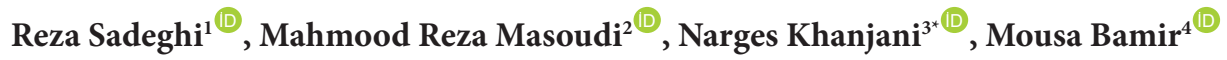 \\ ${ }^{1}$ Department of Public Health, Sirjan School of Medical Sciences, Sirjan, Iran \\ ${ }^{2}$ Departments of Internal Medicine, Division of Rheumatology, Sirjan School of Medical Sciences, Sirjan, Iran \\ ${ }^{3}$ Neurology Research Center, Kerman University of Medical Sciences, Kerman, Iran \\ ${ }^{4}$ Medical library and Information Science, Sirjan School of Medical Sciences, Sirjan, Iran
}

*Correspondence to: Narges Khanjani, Email: n_khanjani@kmu.ac.ir Citation: Sadeghi R, Masoudi MR, Khanjani N, Bamir M. Neglect of other health services during the corona crisis. Environmental Health Engineering and Management Journal 2021; 8(1): 65-66. doi: 10.34172/EHEM.2021.09.

Received: 18 October 2020 Accepted: 6 December 2020 ePublished: 29 January 2021

\section{Dear Editor,}

The 2019 novel coronavirus (COVID-19) has caused a large global outbreak and has become a major public health issue in many countries (1). COVID-19 was first officially reported from Wuhan, China, on December 31,2019 , and is now a concerning worldwide issue (2), because it can cause severe respiratory symptoms and mortality in susceptible individuals (3).

The COVID-19 outbreak has led to an unprecedented global health crisis, challenging the health systems' preparedness and the ability to cope with a highly contagious disease (4). The impact of COVID-19 has been beyond imagination, and is a sparkling global mourning, and booming the feelings of unsafety and uncertainty (4).

Providing proper health services during the COVID-19 pandemic has now become one of the major concerns of the health system (5). On the other hand, uninfected people have become reluctant to visit clinics and health services, due to the possibility of getting infected by the inauspicious virus (6). Some people halted collecting their medicines, or did not refer to health care centers for doing their medical tests and checkups, because they did not feel safe to visit clinics and pharmacies during the epidemic $(7,8)$. Patients with some diseases such as diabetes, hypertension, obesity, and coronary heart diseases, were announced to be more susceptible to COVID-19, although these diseases could be fatal or debilitating themselves, if neglected or left untreated (9).

Andrade has raised many concerns in developing countries, and reported that many women are not receiving antenatal care, including access to necessary antenatal medical check-ups, and children are not been taken to health centers for being immunized (10). The results of a study by Barone et al on the impact of COVID-19 on patients with diabetes in Brazil showed that the majority monitored their blood glucose level at home during the pandemic (91.5\%), but more than half (59.4\%) experienced an increase, a decrease or a higher variability in blood glucose levels, $38.4 \%$ postponed their medical appointments and/or routine examinations, and 59.5\% reduced their physical activity (4).

The health system of countries includes individuals, institutions, and resources that provide health services to meet the health needs of the target population. There is a wide range of health systems around the world with different histories and organizational structures (11). Basically, countries must design and develop health systems according to their needs and resources (12).

Health system quality and quantity must be carefully considered and monitored in the design and delivery of services (13). Failure to pay attention to the various health needs of the population, can lead to increased morbidity, mortality, and health-related problems (14).

However, the COVID-19 pandemic is causing significant changes in the healthcare system, disrupting routine medical practices, and leaving large numbers of patients with insufficient or no care (9). Some primary care practices are reporting reductions in the use of primary health care services up to $70 \%$ (15). Although, the provision of sufficient resources for maternal and child health, midwifery, vaccination, and chronic diseases such as diabetes and cardiovascular diseases is vital.

The health system should be able to create a safe environment for providing all health services and inform patients about the availability of these services. This can be established with taking appropriate actions such as measuring the body temperature of clients before letting them enter the clinic, equipping the building with proper ventilation, making hand sanitizer available for all visitors, maintaining social distance, and other measures. 
Appropriate planning should be done to provide safe and quality services to all patients, during outbreaks such as COVID-19, otherwise, the increase in mortality and morbidity from other medical conditions can be alarming.

\section{Acknowledgments}

The authors would like to gratitude the Sirjan School of Medical Sciences and who participated in this study.

\section{Ethical issues}

The authors certify that this manuscript is the original work of the authors, all data collected during the study are presented in this manuscript, and no data from the study has been or will be published separately.

\section{Competing interests}

The authors declare that they have no conflict of interests.

\section{Authors' contributions}

All authors contributed equally to the data collection, analysis, and interpretation. All authors critically reviewed, refined, and approved the manuscript.

The authors declare that they have no conflict of interest.

\section{References}

1. Lai CC, Shih TP, Ko WC, Tang HJ, Hsueh PR. Severe acute respiratory syndrome coronavirus 2 (SARS-CoV-2) and coronavirus disease-2019 (COVID-19): the epidemic and the challenges. Int J Antimicrob Agents 2020; 55(3): 105924. doi: 10.1016/j.ijantimicag.2020.105924.

2. Abdi M. Coronavirus disease 2019 (COVID-19) outbreak in Iran: actions and problems. Infect Control Hosp Epidemiol 2020; 41(6): 754-5. doi: 10.1017/ice.2020.86.

3. Acter T, Uddin N, Das J, Akhter A, Choudhury TR, Kim S. Evolution of severe acute respiratory syndrome coronavirus 2 (SARS-CoV-2) as coronavirus disease 2019 (COVID-19) pandemic: a global health emergency. Sci Total Environ 2020; 730: 138996. doi: 10.1016/j.scitotenv.2020.138996.

4. Barone MT, Harnik SB, de Luca PV, Lima BL, Wieselberg
RJ, Ngongo B, et al. The impact of COVID-19 on people with diabetes in Brazil. Diabetes Res Clin Pract 2020; 166: 108304. doi: 10.1016/j.diabres.2020.108304.

5. Adalja AA, Toner E, Inglesby TV. Priorities for the US Health community responding to COVID-19. JAMA 2020; 323(14): 1343-4. doi: 10.1001/jama.2020.3413.

6. Adams JG, Walls RM. Supporting the health care workforce during the COVID-19 global epidemic. JAMA 2020; 323(15): 1439-40. doi: 10.1001/jama.2020.3972.

7. Gentile S, Strollo F, Ceriello A. COVID-19 infection in Italian people with diabetes: lessons learned for our future (an experience to be used). Diabetes Res Clin Pract 2020; 162: 108137. doi: 10.1016/j.diabres.2020.108137.

8. Kluge HH, Wickramasinghe $\mathrm{K}$, Rippin HL, Mendes R, Peters DH, Kontsevaya A, et al. Prevention and control of non-communicable diseases in the COVID-19 response. Lancet 2020; 395(10238): 1678-80. doi: 10.1016/s01406736(20)31067-9.

9. Bloomgarden ZT. Diabetes and COVID-19. J Diabetes 2020; 12(4): 347-8. doi: 10.1111/1753-0407.13027.

10. Andrade C. COVID-19: humanitarian and health care crisis in a third world country. J Clin Psychiatry 2020; 81(3). doi: 10.4088/JCP.20com 13383.

11. White F. Primary health care and public health: foundations of universal health systems. Med Princ Pract 2015; 24(2): 103-16. doi: 10.1159/000370197.

12. Chen L, Evans T, Anand S, Boufford JI, Brown H, Chowdhury $M$, et al. Human resources for health: overcoming the crisis. Lancet 2004; 364(9449): 1984-90. doi: 10.1016/s0140-6736(04)17482-5.

13. Roder-DeWan S. Health system quality in the time of COVID-19. Lancet Glob Health 2020; 8(6): e738-e9. doi: $10.1016 / \mathrm{s} 2214-109 x(20) 30223-0$.

14. World Health Organization (WHO). Meeting to Develop a Global Consensus on Preconception Care to Reduce Maternal and Childhood Mortality and Morbidity: World Health Organization Headquarters, Geneva, 6-7 February 2012: Meeting Report. Geneva: WHO; 2013.

15. Cutler D. How will COVID-19 affect the health care economy? JAMA 2020; 323(22): 2237-8. doi: 10.1001/ jama.2020.7308. 